\title{
A STUDY OF VOICE CHANGES IN SPASMODIC DYSPHONIA AFTER BOTULINUM THERAPY
}

\author{
Sanajeet Kumar Singh ${ }^{1}$, Arun Yadav², Suresh Mokamati3 , Jeevan Ramachandra Galagali4, Manoj Kumar Kanzhuly5, Nikhil Kumar6, \\ Kamal Deep Joshi', Abhipsa Hota ${ }^{8}$
}

1 Professor, Department of ENT, Armed Forces Medical College, Pune.

2Officer in charge, Department of ENT, Military Hospital, Pathankot.

${ }^{3}$ Resident, Department of ENT, Armed Forces Medical College.

4 Senior Advisor \& HOD, Department of ENT, CH (SC), Pune.

${ }^{5}$ Associate Professor, Department of ENT, Armed Forces Medical College, Pune.

${ }^{6}$ Resident, Department of ENT, Armed Forces Medical College.

${ }^{7}$ Resident, Department of ENT, Armed Forces Medical College.

${ }^{8}$ Resident, Department of ENT, Armed Forces Medical College.

ABSTRACT
BACKGROUND
Spasmodic dysphonia is a neurological disorder, which can give the voice a strained quality. There is currently no cure for
spasmodic dysphonia. The most common treatment for spasmodic dysphonia is the injection of botulinum toxin.

\section{METHODS}

Botulinum toxin A injection was performed in 10 patients with adductor spasmodic dysphonia. Voice handicap index scoring and voice analysis was done pre- and post-injection. Fundamental frequency, standard deviation of fundamental frequency, jitter, shimmer, mean phonation time and voice noise energy was studied in voice analysis. These voice parameters were measured from sustained phonation of vowel /a/.

\section{RESULTS}

Results of study indicated,

a) Spasmodic dysphonia patients had high mean values for voice handicap index score and all voice parameters.

b) All parameters were reduced significantly post botulinum therapy, but remained higher than their normal value.

c) All voice parameters except jitter showed strong positive correlation with voice handicap index in all domains. Jitter showed moderate positive correlation with total score, physical and emotional domain and strong positive correlation with functional domain.

\section{CONCLUSION}

Botulinum toxin A injection improves voice in cases of spasmodic dysphonia, significantly still post procedure voice does not return to normal.

\section{KEYWORDS}

Spasmodic Dysphonia; Botulinum Toxin A.

HOW TO CITE THIS ARTICLE: Singh SK, Yadav A, Mokamati S, et al. A study of voice changes in spasmodic dysphonia after botulinum therapy. J. Evolution Med. Dent. Sci. 2016;5(22):1152-1155, DOI: 10.14260/jemds/2016/268

\section{INTRODUCTION}

Spasmodic dysphonia (SD) is a neurological disorder affecting the voice muscles in the larynx. In spasmodic dysphonia, intrinsic muscles of larynx experience sudden involuntary movements, which interfere with the ability to produce voice. Spasmodic dysphonia causes voice breaks and can give the voice a tight, strained quality. It is a rare voice disorder with a prevalence rate of $1-4$ per 100000 population. Spasmodic dysphonia is more common in females and sex ratio reported in literature for spasmodic dysphonia ranges from $\sim 1: 1$ to $1: 4$.

Spasmodic dysphonia was thought to be a psychological condition and was described initially as a type of psychoneurosis from either occupational stress or emotional trauma. Spasmodic dysphonia is now reclassified as a form of focal dystonia of unknown aetiology, a neurological disorder that affects muscle tone in one part of the body. Symptoms of

Financial or Other, Competing Interest: None.

Submission 28-01-2016, Peer Review 27-02-2016,

Acceptance 04-03-2016, Published 15-03-2016.

Corresponding Author:

Dr. Suresh Mokamati,

Resident, Armed Forces Medical College,

Pune, India

E-mail: drsuresh.mokamati@gmail.com

DOI: $10.14260 /$ jemds/2016/268 spasmodic dysphonia generally develop gradually and may follow an upper respiratory infection, trauma, voice overuse or stress.

\section{Spasmodic Dysphonia is classified into three types}

a) Adductor spasmodic dysphonia (ADSD)

b) Abductor spasmodic dysphonia (ABSD)

c) Mixed type spasmodic dysphonia (MSD)

Diagnosis of spasmodic dysphonia is essentially clinical based on quality of voice. There is currently no cure for spasmodic dysphonia and treatment can only help reduce its symptoms. The most common treatment for spasmodic dysphonia is the injection of very small amounts of botulinum toxin directly into the affected muscles of the larynx.[1] The toxin weakens muscle by blocking the nerve impulse to the muscle, which is known as Chemodenervation. When injected into a muscle, botulinum toxin effectively denervates that muscle by temporarily blocking the release of acetylcholine at the neuromuscular junction.[2,3] Over a period of time (Typically three to four months), the affected nerve endings recover and spasmodic symptoms gradually return.

As a natural process, axons re-sprout to form neuromuscular junctions in response to the blockage.[4] Botulinum toxin injections generally improve the voice for a 
period of three to four months, after which the voice symptoms gradually return.[1,5,6,7]

Behavioral therapy and voice therapy are another form of treatment that may work in mild cases or can be used with pharmacotherapy as adjunct for increasing the duration of effect. Others may benefit from psychological counselling to help them accept and live with their voice problem.[1,7,8]

In some cases, augmentative and alternative devices can help people with spasmodic dysphonia to communicate more easily. They can help amplify a person's voice over the phone. When more conventional measures have failed, surgery on the larynx may be performed in the form of Thyroplasty type-II. Long-term benefits and effects of this procedure are unknown. [9]

\section{MATERIAL AND METHODS}

A prospective study to evaluate voice changes in cases of spasmodic dysphonia was carried out from Oct 2011 to Oct 2013. All suspected cases presenting to voice clinic of our department were evaluated with detailed history, clinical examination and video-laryngoscopy. Patients with history of laryngo-tracheal injury, laryngeal surgery, organic laryngeal pathology and previously treated with Botulinum toxin A were excluded from study. Total 10 cases diagnosed to have spasmodic dysphonia were selected for study and consent was obtained from all the patients. Voice evaluation was done using Vocal Handicap Index (VHI Form) and Voice analysis in all the cases pre- and post-Botulinum toxin A injection.

Botulinum toxin A (1.5-4 units) was injected into Thyroarytenoid muscle bilaterally under EMG guidance.[10] Botulinum toxin was injected by using a 27-gauge EMG needle, which also functions as a monopolar electrode and a ground electrode was strapped over lower arm.

To treat the thyroarytenoid muscle, the patient was placed in supine position with the neck extended by using a shoulder bag. Skin was cleaned with alcohol based disinfectant solution. The needle is inserted through the skin $2-3 \mathrm{~mm}$ lateral from the midline at the level of the cricothyroid membrane; needle is advanced in posterior, superior $\left(45^{\circ}\right)$ and lateral $\left(45^{\circ}\right)$ direction toward the side of target thyroarytenoid muscle. Once the needle is inside thyroarytenoid muscle LEMG demonstrates motor unit potential, the patient is asked to phonate at this time and change in visual and voice signal due to recruitment confirms placement and botulinum toxin is injected.

Standard dilution of Botulinum toxin A (BOTOX) was used, 100 units diluted in $4 \mathrm{~mL}$ of saline ( 25 units $/ \mathrm{mL}$ ). Dose recommended for spasmodic dysphonia is 1.5-4 units, due to small size of laryngeal muscles volume of injection is kept at $0.1 \mathrm{~mL}$ ( 2.5 units) to prevent dyspnoea. Patients were started with dose of 1.5 units and dose was titrated upwards in partial response with each injection. Adverse effects observed by our patients were pain at injection site and breathiness in initial period lasting few days to 2 weeks. No treatment was required for these known adverse effect of mild severity and transient nature as Botulinum toxin is known to cause post injection breathiness lasting for 1-2 weeks.[11,12]

Patients were followed up at 2 weeks, 2 months and 6 months/on recurrence of symptoms. Post therapy voice analysis was done after 2 months. Master chart of data was made on Microsoft office excel worksheet and Statistical analysis of the data was done to find the correlation between the changes in voice handicap index score and changes in voice analysis parameter scores following botulinum therapy.

\section{RESULTS}

The 10 patients treated comprised 4 males (mean age 39.5 years; range 35-46 years) and 6 females (mean age 52.6 years; range 42-65 years). Mean age for all patients was 47.4 years and range 35-65 years (Table 1).

Voice analysis and voice handicap index scoring was done in pre as well as post injection period for all 10 patients.

Voice analyses was suggestive of significant improvement in following voice parameters - standard deviation of fundamental frequency, jitters, shimmer, mean phonation time and voice noise energy (Table 2).

Voice handicap index scoring was suggestive of significant improvement in all domain scores and total score (Table 3).

Correlation factor between voice analysis data and voice handicap index score was calculated using Microsoft excel spreadsheet (Windows 7). All voice analysis parameters except jitter displayed strong positive correlation with voice handicap index data. Jitter showed strong positive correlation with voice handicap score-functional domain and moderate positive correlation with total score, voice handicap scorephysical domain as well as voice handicap score-emotional domain (Table 4).

\begin{tabular}{|c|c|}
\hline Mean age of patients & 47.4 Year \\
\hline Mean age of male patients & 39.5 Year \\
\hline Mean age of female patients & 52.6 Year \\
\hline Age range for patients & $35-65$ Years \\
\hline Age range for male patients & $35-46$ Years \\
\hline Age range for female patients & $42-65$ Years \\
\hline Sex ratio (M:F) & $1: 1.5$ \\
\hline \multicolumn{2}{|c|}{ Table 1: Demographic Distribution of Subjects } \\
\hline
\end{tabular}

\begin{tabular}{|c|c|c|c|c|}
\hline & $\begin{array}{c}\text { Pre } \\
\text { Injection }\end{array}$ & $\begin{array}{c}\text { Post } \\
\text { Injection }\end{array}$ & Difference & Significance \\
\hline $\begin{array}{c}\text { SD (F0) } \\
\text { (Standard } \\
\text { deviation of } \\
\text { fundamental } \\
\text { frequency) }\end{array}$ & $9.188 \mathrm{~Hz}$ & $6.276 \mathrm{~Hz}$ & $2.912 \mathrm{~Hz}$ & $\begin{array}{c}\text { Significant } \\
(\mathrm{P}<0.001)\end{array}$ \\
\hline Jitter & $1.158 \%$ & $0.629 \%$ & $0.529 \%$ & $\begin{array}{c}\text { Significant } \\
(\mathrm{P}<0.02)\end{array}$ \\
\hline Shimmer & $4.122 \%$ & $3.186 \%$ & $0.936 \%$ & $\begin{array}{c}\text { Significant } \\
(\mathrm{P}<0.001)\end{array}$ \\
\hline $\begin{array}{c}\text { MPT } \\
\text { (Mean } \\
\text { phonation } \\
\text { time) }\end{array}$ & $6.535 \mathrm{sec}$ & $\begin{array}{c}11.848 \\
\mathrm{sec}\end{array}$ & $-5.313 \mathrm{sec}$ & $\begin{array}{c}\text { Significant } \\
(\mathrm{P}<0.001)\end{array}$ \\
\hline $\begin{array}{c}\text { NNE } \\
\text { (Voice noise } \\
\text { energy) }\end{array}$ & -8.048 & -11.79 & $3.742 \mathrm{~dB}$ & $\begin{array}{c}\text { Significant } \\
(\mathrm{P}<0.001)\end{array}$ \\
\hline
\end{tabular}

Table 2: Pre and Post Botulinum Toxin A Injection Voice Analysis Data of Patients 


\begin{tabular}{|c|c|c|c|c|}
\hline & $\begin{array}{c}\text { Pre } \\
\text { Injection }\end{array}$ & $\begin{array}{c}\text { Post } \\
\text { Injection }\end{array}$ & Difference & Significance \\
\hline $\begin{array}{c}\text { Voice } \\
\text { handicap } \\
\text { index }\end{array}$ & 78.7 & 45.8 & 32.9 & $\begin{array}{c}\text { Significant } \\
(\mathrm{P}<0.001)\end{array}$ \\
\hline $\begin{array}{c}\text { Voice } \\
\text { handicap } \\
\text { index - } \\
\text { Functional } \\
\text { domain }\end{array}$ & 26.3 & 15.5 & 10.8 & $\begin{array}{c}\text { Significant } \\
(\mathrm{P}<0.02)\end{array}$ \\
\hline $\begin{array}{c}\text { Voice } \\
\text { handicap } \\
\text { index - } \\
\text { Physical } \\
\text { domain }\end{array}$ & 28.8 & 15.2 & 13.6 & $\begin{array}{c}\text { Significant } \\
(\mathrm{P}<0.001)\end{array}$ \\
\hline $\begin{array}{c}\text { Voice } \\
\text { handicap } \\
\text { index - } \\
\text { Emotional } \\
\text { domain }\end{array}$ & 23.6 & 15.1 & 8.5 & $\begin{array}{c}\text { Significant } \\
(\mathrm{P}<0.001)\end{array}$ \\
\hline \multicolumn{2}{|c|}{ Table 3: Pre and Post Botulinum Toxin A Injection Voice } \\
Handicap Index Score of Patients
\end{tabular}

\begin{tabular}{|c|c|c|c|c|}
\hline & $\begin{array}{c}\text { VHI } \\
\text { (Voice } \\
\text { handicap } \\
\text { index) }\end{array}$ & $\begin{array}{c}\text { VHI-IF } \\
\text { (Voice } \\
\text { handicap } \\
\text { index- } \\
\text { Functional } \\
\text { domain) }\end{array}$ & $\begin{array}{l}\text { VHI-IIP } \\
\text { (Voice } \\
\text { handicap } \\
\text { index- } \\
\text { Physical } \\
\text { domain) }\end{array}$ & $\begin{array}{c}\text { VHI-IIIE } \\
\text { (Voice } \\
\text { handicap } \\
\text { index- } \\
\text { Emotiona } \\
\text { 1 domain) }\end{array}$ \\
\hline $\begin{array}{l}\text { SD (F0) } \\
\text { (Standard } \\
\text { deviation of } \\
\text { fundamental } \\
\text { frequency) }\end{array}$ & $\begin{array}{c}\text { STRONG + } \\
(0.847)\end{array}$ & $\begin{array}{c}\text { STRONG + } \\
(0.890)\end{array}$ & $\begin{array}{c}\text { STRONG + } \\
(0.890)\end{array}$ & $\begin{array}{c}\text { STRONG + } \\
(0.913)\end{array}$ \\
\hline Jitter & $\begin{array}{c}\text { MODERATE } \\
(0.501)\end{array}$ & $\begin{array}{c}\text { STRONG + } \\
(0.890)\end{array}$ & $\begin{array}{c}\text { MODERATE } \\
(0.576)\end{array}$ & $\begin{array}{c}\text { MODERA } \\
\text { TE } \\
(0.618) \\
\end{array}$ \\
\hline Shimmer & $\begin{array}{c}\text { STRONG + } \\
(0.999)\end{array}$ & $\begin{array}{c}\text { STRONG + } \\
(0.995)\end{array}$ & $\begin{array}{c}\text { STRONG + } \\
(0.995)\end{array}$ & $\begin{array}{c}\text { STRONG + } \\
(0.988)\end{array}$ \\
\hline $\begin{array}{c}\text { MPT } \\
\text { (Mean } \\
\text { phonation } \\
\text { time) }\end{array}$ & $\begin{array}{c}\text { STRONG + } \\
(0.862)\end{array}$ & $\begin{array}{c}\text { STRONG + } \\
(0.904)\end{array}$ & $\begin{array}{c}\text { STRONG + } \\
(0.904)\end{array}$ & $\begin{array}{c}\text { STRONG + } \\
(0.925)\end{array}$ \\
\hline $\begin{array}{c}\text { NNE } \\
\text { (Voice noise } \\
\text { energy) } \\
\end{array}$ & $\begin{array}{c}\text { STRONG + } \\
(0.999)\end{array}$ & $\begin{array}{c}\text { STRONG + } \\
(0.997)\end{array}$ & $\begin{array}{c}\text { STRONG + } \\
(0.997)\end{array}$ & $\begin{array}{c}\text { STRONG + } \\
(0.991)\end{array}$ \\
\hline $\begin{array}{r}\text { Table 4: } \\
\text { Han }\end{array}$ & $\begin{array}{r}\text { elation } \\
\text { o Index } \\
\text { Botu }\end{array}$ & $f D$ & $\begin{array}{l}\text { sis Da } \\
\text { fore ar } \\
\text { ion }\end{array}$ & Voice \\
\hline
\end{tabular}

of 30 items, which assess the impact of the voice disorder on physical, functional and emotional aspects of the patient's quality of life.

In our study, pre-procedure evaluation of voice done by voice handicap index showed high score for all mean scores. Total mean VHI score in this study was 78.7, which presented a high level of voice impairment (normal VHI score <20). All three domain scores were also abnormally high with highest impairment seen in physical domain (VHI-II P) with mean score of 28.8; this was followed by function domain score (VHI-I F) of 26.3 and lowest score was observed in emotional domain (VHI-III E) with a mean score of 23.6.

Post Botulinum therapy voice evaluation showed improvement in voice of patients and significant reduction in total and domain VHI scores. Mean total VHI score was 45.8 post-therapy with a reduction of 32.9 in total score. This shows $41.8 \%$ improvement in total score. Similarly, all domain scores showed improvement post therapy with maximum improvement seen in physical domain (VHI-IIP) numerical improvement of 13.6 and percent change of $47.22 \%$. This was followed by improvement in functional domain with change of 10.8 in mean score and 41.06 percentage reduction; emotional domain showed least improvement from initial scores with change of 8.5 in mean score and 36.01 percentage reduction. Changes in total VHI score as well as all domain scores were found to be statistically significant with $P$ value $<0.001$ for all four set of data.

Voice analysis was performed with Dr. Speech voice analysis software and following parameters were used

1. Fundamental frequency (F0) (Hz).

2. Male (mean $120 \mathrm{~Hz}$; normal range $85-180 \mathrm{~Hz}$ ).

3. Female (mean $210 \mathrm{~Hz}$; normal range 165-255 Hz).

4. Standard deviation F0 (Hz) - Normal level $<3.0$.

5. Jitter (\%) - Normal level $<0.5 \%$.

6. Shimmer (\%) - Normal level $<3.0 \%$.

7. Maximum Phonation Time (MPT).

8. Males 25-35 Sec.

9. Females $15-25 \mathrm{Sec}$.

10. Voice noise energy $<-10 \mathrm{~dB}$.

Voice spectrum in voice analysis consists of a series of sine waves and lowest of these harmonics (First harmonic) is known as fundamental frequency (F0). This is calculated from the period of time taken to complete one vibratory cycle and represented as Hertz per second. F0 largely depends on anatomical structure of larynx which is different for males and females. Change in fundamental frequency was $-0.29 \mathrm{~Hz}$ in our study and was found to be non-significant ( $\mathrm{P}$ value $>0.10$ ).

Standard deviation of fundamental frequency (SD F0) can be taken as an indicator of regularity of pitch of voice. Thus a voice with many pitch brakes and variations in pitch has a high standard deviation value. Any effective treatment must reduce standard deviation significantly from pre-therapy level. Pre-therapy mean standard deviation of fundamental frequency (SD F0) score was $9.18(\mathrm{~Hz})$ and post-therapy score was $6.27(\mathrm{~Hz})$. Change in standard deviation of fundamental frequency was $2.91(\mathrm{~Hz})$ and found to be significant with $\mathrm{P}$ value $<0.001$. SD F0 reduced with botulinum therapy in our study.

Jitter is defined as cycle to cycle change in frequency and is a perturbation measure, which measures change in 
frequency during sustained phonation. Pathological voice samples have higher levels of jitter then normal voice and in our study jitter value changed from $1.15 \%$ to $0.62 \%$. Jitter level reduced significantly with botulinum, it still remained higher than normal level of 0.5 .

Similarly, shimmer is a perturbation measure which measures change in intensity during sustained phonation; shimmer levels are more commonly deranged in voice disorders than jitter. Mean shimmer value changed from $4.12 \%$ (Pre) to $3.18 \%$ (Post) with change of $0.94 \%$. This was found to be significant on analysis with $P$ value $<0.001$. Post therapy shimmer values remained above the normal level (3\%).

Maximum Phonation Time (MPT) is the longest period, during which a patient can sustain phonation of a vowel sound. Because of its simplicity and ease of use, Maximum Phonation Time (MPT) is a frequently used clinical tool to assess vocal function. Maximum Phonation Time (MPT) was expected to increase with botulinum therapy in adductor spasmodic dysphonia cases due to decrease in vocal cord adduction, which causes abrupt loss of voice. In our study, maximum phonation time was almost doubled in post therapy period. Mean Maximum Phonation Time (MPT) value changed from $6.53 \mathrm{sec}$ (Pre) to $11.84 \mathrm{sec}$ (Post) with change of $5.313 \mathrm{sec}$. MPT also improved after treatment, but stayed well below normal levels for both males and females.

Normalised Noise Energy (NNE) assesses the relative level of vocal noise to that of harmonics like Harmonics-toNoise Ratio (HNR), but NNE bases the analysis on a relatively small number of vocal periods and is therefore much faster to calculate. This has an added advantage that it avoids the effect of drift in fundamental frequency or intensity during testing, which can be problem in the calculation of the noise component of the HNR. Mean Normalised Noise Energy (NNE) changed from $-8.04 \mathrm{~dB}$ (Pre) to - 11.84 (Post) with change of $3.74 \mathrm{~dB}$. This was found to be significant on analysis.

Analysis of Voice handicap index data (total score and three domain scores) and voice analysis data was done to find out Spearman's rank correlation coefficient.

\section{This coefficient ranges between +1 to -1 and was classified as following: \\ 1. Perfect correlation (Value of 1 and -1 ). \\ 2. No correlation (Value of 0 ). \\ 3. Mild correlation (Value between+/- 0.1 to 0.3 ). \\ 4. Moderate correlation (Value between $+/-0.4$ to 0.7 ). \\ 5. Strong correlation (Value between $+/-0.8$ to 0.9 ).}

Out of six parameters evaluated in this study, fundamental frequency (F0) showed weak negative correlation with total VHI score, VHI - I F, VHI - II P and weak positive correlation with VHI - III E. Jitter showed moderate positive correlation with total VHI score, VHI - II P, VHI - III E and strong positive correlation with VHI - I F. Other four parameters (SD F0, Shimmer, MPT, NNE) were found to have strong positive correlated with total VHI score as well as three domain scores.

Botulinum toxin injections into thyroarytenoid muscle provide an effective treatment for adductor spasmodic dysphonia and voice changes post botulinum therapy can be measured by both voice handicap index and voice analysis. Voice handicap index is a tool, which is widely used across the world for voice disorders and this provides patient perspective about disease. Voice analysis of voice provides objective data of patient's voice which can be used to assess severity of disease, comparison between pre- and posttreatment results and for medico legal purpose also. In our study, we documented change in voice by voice handicap index as well as voice analysis for all patients and data was analysed to find correlation coefficient between different parameters of both (VHI and voice analysis).

All five parameters of voice analysis with significant post therapy change were found to have positive correlation with VHI scores. Therefore, voice analysis can be used effectively to monitor progress of patient in spasmodic dysphonia, as it correlates well with stage and severity of disease measured by Voice Handicap Index (VHI).

\section{REFERENCES}

1. Watts CCW, Whurr R, Nye C. Botulinum toxin injections for the treatment of spasmodic dysphonia. Cochrane Database of Systematic Reviews 2004;Issue 3:Art No. CD004327. DOI: 10.1002/14651858.CD004327.

2. Pearson EJ, Sapienza CM. Historical approaches to the treatment of adductor-type spasmodic dysphonia (ADSD): a review and tutorial. Neuro Rehabilitation 2003;18:325-338.

3. Sapienza CM, Walton S, Murry T. Acoustic variations in adductor spasmodic dysphonia as a function of speech task. Journal of Speech, Language, and Hearing Research 1999;42:127-140.

4. Whurr R, Nye C, Lorch M. Meta-analysis of botulinum toxin treatment of spasmodic dysphonia: a review of 22 studies. International journal of Language and Communication Disorders 1998;33:327-329.

5. Blitzer A, Brin MF, Fahn S, et al. Localized injections of botulinum toxin for the treatment of focal laryngeal dystonia. Laryngoscope 1988;98(2):193-7.

6. Novakovic D, Waters HH, D'elia JB, et al. Botulinum toxin treatment of adductor spasmodic dysphonia: longitudinal functional outcomes. Laryngoscope 2011;121(3):52-6.

7. Kieschnick CO, Powell TW. Treatment of spasmodic dysphonia: a brief overview for clinicians. National student speech language hearing association journal 1996;26:14-18.

8. Murry T, Woodson GE. Combined modality treatment of adductor spasmodic dysphonia with botulinum toxin and voice therapy. J Voice 1995;9:460-5.

9. Aronson AE, Desanto LW. Adductor spastic dysphonia: three years after laryngeal nerve section. Laryngoscope 1983;93:1-8.

10. Casserly P, Timon C. Botulinum toxin a injection under electromyographic guidance for treatment of spasmodic dysphonia. J Laryngol Otol 2008;122:52-6.

11. Truong DD, Bhidayasiri R. Botulinum toxin therapy of laryngeal muscle hyperactivity syndromes: comparing different botulinum toxin preparations. European Journal of Neurology 2006;13:36-41.

12. Carolyn R Baylor, Kathryn M Yorkston, Nicole C Maronian. The psychosocial consequences of BOTOX injections for spasmodic dysphonia: a qualitative study of patients' experiences. Journal of Voice 2007;21:231247. 